\title{
Korrespondenzen.
}

\section{Offener Brief von Prof. S. Kitasato an den Herausgeber der Deutschen medizinischen Wochenschrift.}

Tokjo, den 21. September 1920.

Hochverehrter Herr Kollege!

Aus mir zugegangenen deutschen Zeitungen ersehe ich, daß ein von mir an Frau Exzellenz Koch gerichteter Brief in Deutschland teilweise veröffentlicht worden ist ${ }^{1}$ ). Natürlich habe ich nichts dagegen, da das, was ich dort zum Ausdruck gebracht habe, meine autrichtige Ueberzeugung ist.

Mellier Ansicht nach ist bei dem heutigen Zustand der Welt, und zwar an erster Stelle von seiten der W/ssenschaft, mehr nach dem zu streben, was versöhnt und vereinigt als, vielleicht ungewollt, den $\mathrm{HaB}$ zu verewigen und weitere Trennung herbeizuführen. Die Wissenschaft darf sich ihre Flügel durch nıcints binden oder verkürzen lassen und muB sich nach allen Richtungen hin frei und ungehemmt, gefördert von allen Seiten, von Freund und Feind, im Interesse der ganzen leidenden Menschheit, ohne Unterschied der Person, der Nation und der Rasse, entwickeln dürfen. Dies gilt ganz besonders für unsere inedizinische $W$ issenschaft, deren hohes Ideal es ist, keine Wunden zu schlagen, sondern Wunden und Schmerzen zu heilen und Tränen zu trocknen. Während anscheinend Handel und Industrie eine Art Krieg nach dem Kriege führen wollen, hätte ich doch geglaubt, daB die Wissenschaft als solche sich als etwas Höheres zelgen würde und daB sie mit dem Frieden wirklich Frieden schließen würde. Die Wissenschaft jagt doch nich wie der Handel materiellen Gütern nach, sondern befaßt sich mit der Erwerbung allgemeiner, geistiger Güter usw., wie sie nicht nur einzelnen Nationen, sondern der ganzen Welt ohne politische Grenzen zugute kommen sollen.

Auf der Pariser Versammlung ausländischer Vertreter der Wissenschaft war Japan nur nit zwel Nichtmedizinern vertreten. Wären Mediziner mit der Vertretung beauftragt gewesen, hätten sie wahrscheinlich dem dort gefaBten Beschluß nicht zugestimmt und hätten sich völlıge Unabhängigkeit und Freiheit ihrer Handlungen vorbehalten.

Eine Ueberbrückung bestehender Differenzen herbeizuführen suchen, ist nach dem Gefühl und Gedankengange unseres Ostens etwas Edleres und Höheres für die Wissenschaft, als mit der Saat der Uneinigkeit und des Völkerhasses fortzufahren. Es steht zu be. fürchten, da $B$ aus solcher Saat die Palme des Friedens und der Versöhnung nicht entsprießen wird. Heute scheint es allerdings nicht nur nicht leichter, sondern auch populärer zu sein, Zwietracht zu säen als Eintracht.

Gewiß gibt es deutschfeindliche Elemente in Japan, wie es auch japanfeindliche Elemente in Deutschland gibt. Aber in beiden Ländern sind diese Elemente, daran zweifle ich nicht, in der Minorität, und es wäre ein Fehler, einer solchen Minorität ein Vorrecht vor der Majorität einräumen zu wollen.

Jedenfalls steht nicht nur die medizinische Wissenschaft Japans, sondern auch wohl der bei weitem größere Teil der japanischen $W$ issenschaften anderer Gebiete der deutschen Wissenschaft wieder sympathisch und ohne Vorurteil gegenüber, bereit zu gemeinsamer uneigennütziger Forschung, nicht nur zum Nutzen und Segen Deutschlands oder Japans, nein, zum Vorteil der ganzen Welt.

Jede Zeit hat ihren ihr eigenen Geist, der erst von späteren Generationen nach seinen verschiedenen Richtungen hin geprüft gewürdigt und richtig kritisiert werden kann. Das gilt auch ganz besonders für die schwere Zeit, in der wir leben. In heutigen, modernen Kriegen herrscht ein anderer Geist als der, in dem solche in früheren Zeiten vielleicht geführt wurden. Neue Waffen, wie das Aushungern nicht nur von Festungen, sondern von ganzen Völkern, sodaß Frauen und Kinder in modernen Kriegen den Gefahren desselben kaum weniger ausgesetzt sind als der Soldat auf dem Schlachtfelde, wie die Unterseeboote und Luftschiffe usw. haben dem Krieg eine furchtbare Veränderung gegeben, und damit mus die Welt sich abfinden. Die Zeiten sind voruber,

1) D. m. W. Nr. 29 S. 800 . 
wo der Gegner, wie das in früheren Zeiten bei uns in Japan geschehen ist. seinem Feinde Salz sandte. an dem es diestin ginzlich fehlte, um ihn nicht durch andere Waffen als die auf dem Schlachtfelde $z u$ besiegen. Seitdem hat die Well eben große Fortschritte gemacnt. una cin derartiges System der Kriegtülnrung ist jetzt veraltet. Welche Art der Kricgiülirung die bessere oder edlere (wenn man von "edel“ bei einem Kriege uberhaupt sprechen dari) ist, ist nicht meine Silse $z u$ entscheiden. Dies soll nur die Wandelbarkeit der Zeiten und ihrer Ans chten illustrizren.

Ich würde mich freuen, falls auch diese Zeilen, hochverchrter Herr Kollege, wemn auch nur noch so weing, zum Wiederaubau der wissenschattlichen, über dem Nationalitätenstreit stehenden Be-

ziehungen zwischen Deutschland und Japan beitragen. Dis deutsche Sprache wird nach wie vor von der heranwachsenden Jugend Japans, den Vertretern der Zukuilit, fleißig galernt, u.ıd es wuirde bedauerlich sein, wenn diese Bestrebungen durch Mißverständuisse der

Wissenschaft beider Länder, die sich über die tigiiche Politik zu erlseben imstande seill sollte, einen Abbrucl crieiden sollten.

Die Gelegenhcit benutzend, sehr gechter Herr Kollege, Ihnen für jeden Dienst zu danken, den Sie der japanischen Jugend in Deutschland erwiesen haben und erweisen mögen, verbleibe ich

mit ergebensten Gruß

Ihr S. Kitas ato 